IJMS 18 (1), 155-172 (2011)

\title{
IT - BUSINESS STRATEGIC ALIGNMENT IN INFLUENCING SUSTAINABLE COMPETITIVE ADVANTAGE IN JORDAN: STRUCTURAL EQUATION MODELLING (SEM) APPROACH
}

\author{
DAMNITHAN AL-MAJALI \\ ZULKHAIRI MD. DAHALIN \\ UUM College of Arts \& Sciences \\ Universiti Utara Malaysia
}

\begin{abstract}
In many review articles or studies, the researchers have encouraged further exploration on the causal links between Information Technology (IT) investments and a firm's sustainable competitive advantage. The outcomes of empirical studies have been inconclusive, which is to a certain extent due to the omission of IT-business strategic alignment. Indeed, strategic alignment has emerged as one of the most important issues facing business and IT executives all over the world. This paper reports on the empirical investigation of the success factors, which consist of leadership, structure and process, service quality, and values and beliefs, which are representative of the culture gap between IT strategy and business strategy. A questionnaire survey among 200 IT managers was carried out and 172 data sets were collected. This represented a $86 \%$ response rate. After a rigorous data screening process including outliers, normality, reliability and validity, 172 data sets were ready for structural equation modelling (SEM) analysis. Confirmatory Factor Analysis (CFA) was performed to examine the composite reliability, convergent validity and goodness of fit of the individual constructs and measurement models. The revised structural model demonstrates the relationships between all the four exogenous variables and IT-business strategic alignment, and all the four exogenous variables and sustainable competitive advantage. In addition, regarding the revised model there are two mediating effects of strategic alignment in the relationship between leadership, structure and process, service quality, values and beliefs, and sustainable competitive advantage.
\end{abstract}

Keywords: Strategic alignment, alignment gap, information technology, sustainable competitive advantage. 


\section{Introduction}

In order to improve their performance, firms invest heavily in IT such as hardware, software, network, and data components (Oana, 2010). However, based on the mixed findings of the linkage between IT spending and firm performance, some researchers in the MIS field suggest that IT-business alignment is a construct that can help organizations improve the positive impact of IT on organizational success (e.g. Henderson \& Venkatraman, 1993 ; Luftman \& Brier, 1999; Luftman, 2003; Kearns \& Lederer, 2001; Sabherwal \& Chan, 2001; Croteau \& Bergeron, 2001; Chan, Sabherwal \& Thatcher 2006; Chan \& Reich, 2007; Dong, Liu \& Yin, 2008). For organizations to stay competitive in a dynamic business environment, they have to determine and understand how to manage IT strategically as a key success factor for a successful business in a dynamic business environment that supports business strategies and processes (Henderson \& Venkatraman, 1993). Further, the alignment between the business strategy and the strategic choices of IT deployment is a prominent area of concern that business and IT management struggle with (Johnson \& Lederer, 2010). Strategic alignment refers to "The degree to which the IT mission, objectives and plans support and are supported by the business mission, objectives and plans" (Reich \& Benbasat, 1996 \& 2000). However, regardless of a growing body of research, recent reviewers (Chan et al., 2006; Chan \& Reich, 2007; Masa'deh \& Kuk, 2009) have continuously called for more research into the factors that affect IT-business alignment. Consequently, this study tries to make an original contribution to the existing body of knowledge in the area of MIS by exploring the association between ITbusiness strategic alignment and sustainable competitive advantage. Moreover, the current study will contribute to IT-business strategic alignment literature by investigating a new theoretical approach to strategic alignment that has not been explored in the field of IS. This is done by exploring the relationships between several factors (i.e. leadership, structure and process, service quality, and values and beliefs) on IT-business strategic alignment to achieve sustainable competitive advantage and how strategic alignment can mediate the relationship between these factors and sustainable competitive advantage.

\section{Literature Review}

Despite the criticality of the relationship between business and IT, there have only been a few attempts to investigate the relationship further. Although much has been written about business-IT strategic 
alignment, it concerns the issues of control of resources rather than managing relationships (Ward \& Peppard, 1999). Although the alignment gap represents an important concept in business-IT strategic alignment, it has not been presented or discussed explicitly in the business-IT strategy context. Moreover, none of the earlier studies conducted by researchers indicate who referred to the concept of the alignment gap between business strategy and IT strategy in particular. Therefore, the focus of this paper is to identify and prove this concept and to focus attention on determining the reasons why the alignment gap exists between business strategy and IT strategy. This will provide great benefit to the management in business and industrial organizations to address unmanageable issues resulting from the alignment gap, with different management practices for bridging the alignment gap between business strategy and IT strategy. Although many scholars and authors in past studies have mentioned and discussed the term 'gap' or 'culture gap' in different articles (Ward \& Peppard, 1999; Grindly, 1992; Luftman, 2003), none of these scholars or the authors attempted to provide a critical review of the concept of the "alignment gap" between business strategy and IT strategy in a conceptual manner. Some scholars (e.g. Chan \& Reich, 2007) called for further adjustments to the concept of alignment by applying new theoretical approaches that have not been explored in the field of IT. Therefore, this study aims to conceptualize IT-business strategic alignment into the alignment gap. The concept of the alignment gap between business strategy and IT strategy has emerged due to the fact that there are two separate organizational units in any organization - normally the IT department, which is responsible for IT activities and the business department. Understandably, this has led to the appearance of the gap between the IT functions and the business activities. Generally, IT function refers to the individuals who provide IT services to the organization. These individuals are usually highlyskilled IT professionals who have a certain amount of knowledge and experience in software engineering and technical aspects of computer hardware and software systems, and who carry out a variety of tasks to deal with the requirements of the firm for IT services. Certain functions of the IT professionals may include design, implementation, and maintenance of the software programmes, including data processing (Ward \& Peppard, 2002; Sage, 2002).The concept of 'gap', as used here, is based on the literature and refers to what is called the 'culture gap', which is a variable that explains the challenges that can exist between the IT function and the business activities. The culture gap concept consists of four dimensions, i.e. leadership, structure and process, service quality, and values and beliefs (Ward \& Peppard, 1999). The culture gap has been identified as a key factor in limiting 
the successful utilization of IT in organizations (Grindly, 1992). Leadership is elaborated upon by reflecting both the leadership of the CIO and the leadership of the CEO. Service quality is considered to be vital in determining the customer-supplier relationship. Such relationships could be strengthened by the IT department by focusing on the development of IT outsourcing and the level of service that clients expect from the vendor. The last dimension, values and beliefs, shape how attitudes, behaviours and practices develop. Hence, the values and beliefs of a firm member have great effect on several dimensions of IT, including the way it is managed. Culture is an abstract concept that refers to the organizational culture in the organizational context. It is a shared set of values, behaviours and beliefs together with attitudes and experiences that represent unique characters that take the form of rules of behaviour in a work group or organization (Galliers, Meriali \& Spearing, 1994).The underlying reasons for the misalignment between business and IT include the lack of a common understanding of the concept of strategic alignment, and depend on the classical assumptions for the strategic planning process or ad-hoc IT investments in organizations (Oana, 2010). She further indicated that the misalignment leads to missing competitive advantages and opportunities, increasing wasted time, increasing costs and creating a negative environment for IT investments. Indeed, probably the most common business concept today is competitive advantage. Despite its wide use, few researchers have attempted to define the concept, and it is often confused with distinctive competence (Day, 1994). Porter's (1985) book, titled 'Competitive Advantage' propelled the concept of competitive advantage into the popular business vernacular. Porter did not articulate the definition of the concept but explained that competitive advantage refers to organizational factors that enable a firm to outperform its competitors. As such, Porter argued that sustaining competitive advantage should be the central purpose of an organization's competitive strategy and that creating value is the means for attaining it. As Collis and Montgomery (1995) explained, "competitive advantage, whatever its source, ultimately can be attributed to the ownership of a valuable resource that enables the company to perform activities better or more cheaply than its competitors". Moreover, to be sustainable, a competitive advantage should be difficult to imitate or substitute (Porter, 1985).

\section{Research Conceptual Model}

The aim of this study is to identify factors that might lead to better strategic alignment and its effect on sustainable competitive advantage. In addition, it will identify those factors that might lead to a better 
sustainable competitive advantage through strategic alignment. This conceptual model extends Henderson and Venkatraman's (1993). Furthermore, the model acts as a guideline for organizations to lever their sustainable competitive advantage through strategic alignment. For practitioners, this model will provide a detailed roadmap to guide the decision-making process and to focus their attention on factors that affect sustainable competitive advantage. Figure 2 displays the research model.

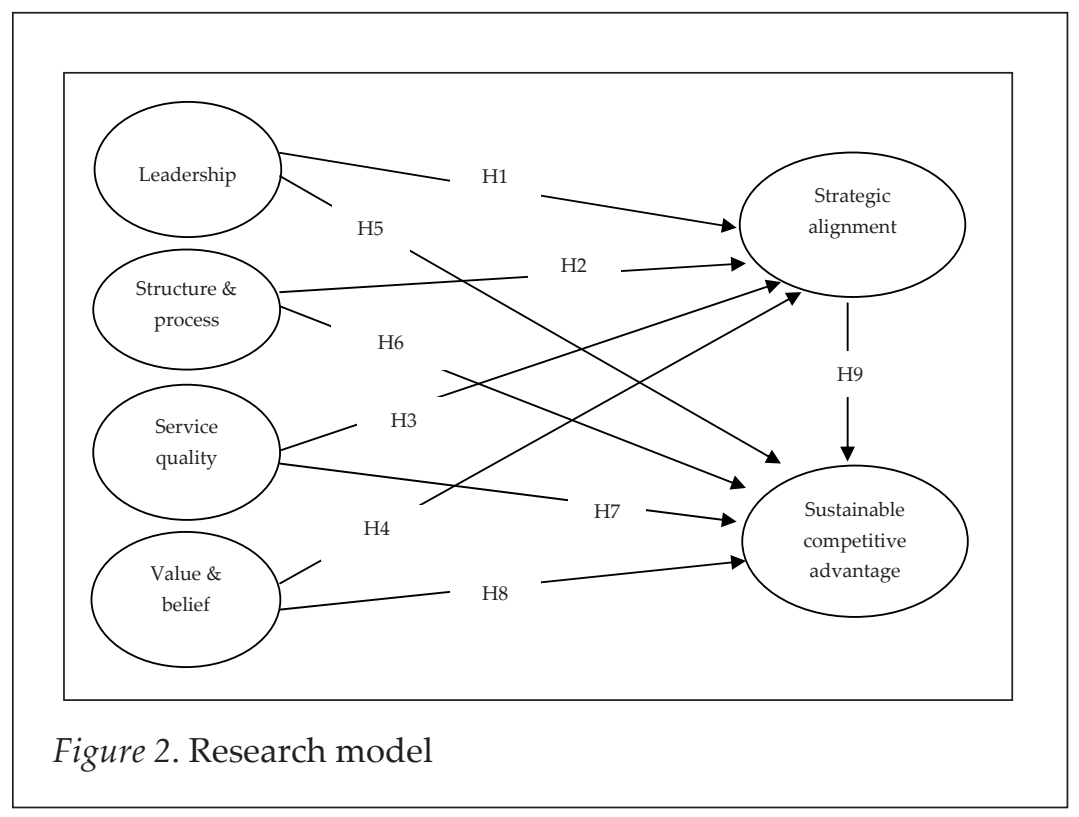

\section{Hypotheses Formulation}

Based on the objectives of the study, thirteen hypotheses were formulated.

H1: The more leadership between business and IT managers, the greater the manager's engagement in strategic alignment.

H2: The more structure and process with the business plan and the IT plan, the greater the manager's engagement in strategic alignment.

H3: The more service quality between the business and the IT managers, the greater the manager's engagement in strategic alignment.

H4: The more values and beliefs in the business plan and the IT plan, the greater the manager's engagement in strategic alignment. 
H5: Firms that pursue strategic alignment will enhance their sustainable competitive advantage.

H6: The more leadership between business and IT managers the greater the manager's effect on sustainable competitive advantage.

H7: The more the structure and process with the business plan and the IT plan, the greater the manager's effect on sustainable competitive advantage.

H8: The more service quality between business and IT managers, the greater the manager's effect on sustainable competitive advantage.

H9: The more the values and beliefs in the business plans and the IT plans, the greater the manager's effect on sustainable competitive advantage.

H10: The strategic alignment will mediate the relationship between leadership and sustainable competitive advantage.

H11: The strategic alignment will mediate the relationship between structure and process and sustainable competitive advantage.

H12: The strategic alignment will mediate the relationship between service quality and sustainable competitive advantage.

H13: The strategic alignment will mediate the relationship between values and beliefs and sustainable competitive advantage.

\section{Methodology}

This study adopts a quantitative approach to the research. The unit of analysis is organizations sampled by IT managers of public shareholding firms in Jordan.

\section{Questionnaire Design and Measurement Scale}

The questionnaire for this study consists of five parts: Part one consists of a cover letter explaining the title of the study and the purpose of the questionnaire; Part two consists of questions concerning the respondents demographic profile; Part three contains the four latent constructs that are hypothesised to influence strategic alignment in Jordan; Part four contains the strategic alignment; and Part five contains the sustainable competitive advantage. These constructs were adapted from previous strategic alignment and sustainable competitive advantage studies, thus, exploratory factor analysis is omitted. The measures are (a) Leadership measured by six items (Ward \& Griffiths, 1996), (b) structure and process measured by six items (Ward \& Peppard ,1999), service quality measured by five items 
Pitt, Watson \& Leavon (1995), values and beliefs measured by six items (Grindly,1992), strategic alignment measured by (Pierce, 2002), sustainable competitive advantage measured by six items consisting of three items that belong (DeVilliers, 2006) and three items derived from operational definition. A seven-point Likert scale with anchors from (1) strongly disagree to (7) strongly agree, was used for all items. The sample frame was determined from the (ASE) Amman Stock Exchange (www.ase.com.jo), which includes 280 of the most powerful public shareholding firms from four sectors. The stratified random sample used 200 respondents who were identified from the South, North and Center of Jordan. The researcher distributed 200 questionnaires to the respondents of which 172 questionnaires were returned. Ten questionnaires were unreturned and another questionnaire was incomplete, leaving (172) questionnaires or $86 \%$ response rate for further analysis.

\section{Data Screening and Analysis}

The 172 dataset was coded and saved into SPSS version 15.0 and analysed using AMOS version 6.0. The data was carefully examined for missing data. For the univariate normality test, Z-skewness scores greater than +3 or -3 were absent. Thus, each item was considered to be normal data (Coakes \& Steed, 2003). Thus, 172 questionnaires remained for final analysis. Subsequently, several statistical validity tests were then conducted including the reliability test, composite reliability tests, confirmatory factor analysis (CFA) for construct convergent validity, discriminate validity for multicollinearity treatment, descriptive analysis and correlation. Subsequently, Structural Equation Modelling (SEM) analysis using AMOS 6.0 was conducted. SEM was selected because it uses confirmatory factor analysis to minimize measurement error through the multiple indicators pr-latent variable, able to estimate both direct and indirect effects, a testable model, and able to ensure consistency of the model with data, and to estimate the effects among the constructs. The SEM analysis produces two structural models, namely, hypothesised structural model and the revised model.

\section{Finding}

\section{Demographic Profile of the Respondents}

The respondents consisted of female (48\%) against males (52\%). The majority of the sample was aged $41(7 \%)$.

IJMS 18 (1), 155-172 (2011) 161 


\section{Descriptive Statistics of Variables}

Table 1 indicates that the six constructs, four exogenous (leadership, structure and process, service quality, values and beliefs); and two endogenous (strategic alignment, and sustainable competitive advantage) have Cronbach's alpha and composite reliability of above 0.60 . This implies that the measurement scales for all the variables are internally consistent and reliable (Nunnally, 1970).

Table 1

Descriptive Statistics of Variables

\begin{tabular}{lccccccccc}
\hline Variables & $\begin{array}{c}\text { Code } \\
\text { No. of Mean S. D } \\
\text { items }\end{array}$ & & & & $\begin{array}{c}\text { Min } \\
\text { (C/alpha) }\end{array}$ & $\begin{array}{c}\text { Max } \\
\text { Reliability }\end{array}$ \\
\hline $\begin{array}{l}\text { Sustainable competitive } \\
\text { advantage }\end{array}$ & SUS & 6 & 5.07 & .650 & 4 & 7 & .82 & .91 \\
Strategic alignment & SA & 6 & 4.92 & .686 & 4 & 6 & .80 & .81 \\
Leadership & LS & 6 & 4.77 & .659 & 4 & 6 & .89 & .95 \\
Structure and process & SP & 6 & 5.22 & .615 & 4 & 7 & .82 & .62 \\
Service quality & SQ & 5 & 5.03 & .495 & 4 & 6 & .66 & .87 \\
Values and beliefs & VB & 6 & 5.37 & 722 & 4 & 7 & .90 & .87 \\
\hline
\end{tabular}

\section{Confirmatory Factor Analysis (CFA) Results}

Survey measures were assessed by one academic staff in Malaysia, and two academic staff in Jordan, who participated in the pilot study and all of them, have professional qualifications in management and IT. The survey was reviewed in Jordan by three IT managers as a sample of the respondents. The managers were professional people working in different industrial sectors of the Jordanian public listed companies, with significant experience in management and IT fields. The feedback from the participants revealed several points about the question rating, wording, and length.

From the confirmatory factor analysis result in Table 2, some scholars (e.g. Gerbing Anderson, 1988) argued that CFA can supply a stricter explanation of unidimensionality than other techniques like EFA (exploratory factor analysis). We observed that the factor loadings of all observed variables or items were adequate, at least 0.30 , as suggested by Pallant, (2007). In order to validate the measurement model through CFA (confirmatory factor analysis), it is important to assess each construct for reliability and validity in terms of convergent validity and discriminate validity. Indeed, the standardized regression 
weights for the research's indicators were examined, and it was found that some indicators had a low loading towards the latent variables, in particular

LS3 $=.403 / \mathrm{LS} 4=.468 / \mathrm{LS} 5=431 / \mathrm{LS} 6=453 / \mathrm{SP} 1=.314 / \mathrm{SP} 3=.426 / \mathrm{SP} 5.278 /$

$\mathrm{SP} 6=.322 / \mathrm{SQ} 1=.449 / \mathrm{SQ} 2=.333 / \mathrm{SQ} 3=.321 / \mathrm{VB} 1=.407 / \mathrm{VB} 2=.418 /$

VB $3=.329 / \mathrm{SA} 1=.440 / \mathrm{SA} 2=.421 / \mathrm{SA} 3=.315 / \mathrm{SA} 6=.326 / \mathrm{SUS}=.409 /$ SUS4 $=.310 /$ SUS6 $=.291$.

Moreover, since all of these items did not meet the minimum recommended value of factor loadings of 0.50 (Hair, Black, Babin, Anderson \& Thatham, 1998), and/or because the initial fit indices moderately fit the sample data, they were all removed and excluded from further analysis. This indicates that all the constructs conform to the convergent construct validity test. As shown in Table 2, the remaining number of items for each construct are as follows: sustainable competitive advantage SUS (3 items), strategic alignment ( 2 items), leadership ( 2 items), structure and process ( 2 items), service quality ( 2 items), and values and beliefs VB ( 3 items). The total number items remaining is 14 .

Table 2

Final Confirmatory Factor Analysis Results of All Constructs

\begin{tabular}{|c|c|c|c|}
\hline Variables & $\begin{array}{l}\text { Item } \\
\text { Code }\end{array}$ & Items & Factor $\mathrm{g}$ \\
\hline \multirow[t]{2}{*}{ LS } & LS1 & $\begin{array}{l}\text { There are regular direct meetings between the business and } \\
\text { IT managers. }\end{array}$ & .94 \\
\hline & LS2 & $\begin{array}{l}\text { There is a nominated liaison position between the business } \\
\text { and IT managers. }\end{array}$ & .88 \\
\hline \multirow[t]{2}{*}{ SP } & SP2 & The IT plan reflects business goals. & .45 \\
\hline & SP4 & The business plan refers to the IT plan. & .95 \\
\hline \multirow[t]{2}{*}{ SQ } & SQ4 & IS system offers a very competitive service. & .65 \\
\hline & SQ5 & $\begin{array}{l}\text { Organizations have good relationships with local or } \\
\text { international businesses. }\end{array}$ & .38 \\
\hline \multirow[t]{3}{*}{ VB } & VB4 & $\begin{array}{l}\text { IS for experts must be responsible for consolidating their } \\
\text { organizations. }\end{array}$ & .782 \\
\hline & VB5 & Managers comprehend IS terminology well at all levels. & 782 \\
\hline & VB6 & IS enhances their productivity among the managers. & .797 \\
\hline \multirow[t]{2}{*}{ SA } & SA4 & $\begin{array}{l}\text { Our IT and business planners interact closely in the } \\
\text { formulation of the IT strategic plan. }\end{array}$ & .86 \\
\hline & SA5 & $\begin{array}{l}\text { Our IT planners are aware of the firm's objectives, business } \\
\text { strategies and long-term goal. }\end{array}$ & .83 \\
\hline
\end{tabular}

(continued)

IJMS 18 (1), 155-172 (2011) 163 


\begin{tabular}{llllll}
\hline Variables & $\begin{array}{l}\text { Item } \\
\text { Code }\end{array}$ & & & Factor g \\
\hline SUS & Sus1 & $\begin{array}{l}\text { My organization encourages import new ideas from } \\
\text { outside the organization. }\end{array}$ & .60 \\
& Sus3 & $\begin{array}{l}\text { My organization encourages sharing ideas across } \\
\text { organizational units. }\end{array}$ & .81 \\
& Sus5 $\begin{array}{l}\text { Access to superior limit resources can contribute to } \\
\text { competitive advantages in the market place. }\end{array}$ & .81 \\
\hline
\end{tabular}

\section{Discriminant Validity of Constructs}

Discriminant validity refers to observed constructs that should not be highly correlated to each other (multicollinearity). In other words, observed variables should be discriminating or distinct (Fornell \& Larcker, 1981). To support discriminant validity, the average variance extracted (AVE) should be more than the correlation squared (Fornell \& Larcker, 1981). Table 3 shows the result of the calculated variance extracted (VE) to support the discriminant validity of the constructs. The average variance extracted (AVE) is the average VE values of two constructs (Table 3). The VE is derived from the calculation of variance extracted using the following equation:

Variance Extracted $=\frac{\sum\left(\text { stan dardized } S M C^{2}\right)}{\sum\left(s \tan \text { dardized } S M C^{2}\right)+\varepsilon \sum j}$

Consequently, each AVE value (Table 3) is found to be more than the correlation squared (Table 4), thus, the discriminant validity is supported, i.e. multicollinearity is absent.

Table 3

Variance Extracted of Variables

\begin{tabular}{cc}
\hline Observed Variables & Variance Extracted \\
\hline SUS & .79 \\
SA & .87 \\
LS & .94 \\
SP & .82 \\
SQ & .57 \\
VB & .89 \\
\hline
\end{tabular}

\section{Goodness of Fit Indices}

Confirmatory factor analysis was conducted on each individual construct and measurement model. All CFAs of the constructs produced a relatively good fit as indicated by the goodness of fit

164 IJMS 18 (1), 155-172 (2011) 
indices such as CMIN/df ratio ( $<2)$; p-value $(>0.05)$; Goodness of Fit Index (GFI) of >.95; and root mean square error of approximation (RMSEA) values of less than .08 (<.08) (Hair, Black, Babin, Anderson \& Tatham, 2006; Bagozzi \& Yi, 1988). Table 5 shows that the goodness of fit of the generated or re-specified structural model is better than the hypothesised model.

Table 4

Correlation \& Correlation Square (in Parentheses) Matrix Among Variables

\begin{tabular}{ccccccc}
\hline & VB & SQ & SP & LS & SA & SUS \\
\hline VB & 1.000 & & & & & \\
SQ & $.73(.54)$ & 1.000 & & & & \\
SP & $.85(.16)$ & $.69(.232)$ & 1.000 & & & \\
LS & $.91(.17)$ & $.75(.16)$ & $.88(.217)$ & 1.000 & & \\
SA & $.88(.22)$ & $.72(.14)$ & $.84(.18)$ & $.90(.24)$ & 1.000 & \\
SUS & $.84(.10)$ & $.68(.093)$ & $.80(.112)$ & $.86(.106)$ & $.83(.349)$ & 1.000 \\
\hline
\end{tabular}

Table 5

Revised Model and Hypothesised Model Results

\begin{tabular}{lcc}
\hline Indicators & Revised Model & Hypothesized Model \\
\hline CMIN & 120.755 & 2216.047 \\
Df & 107 & 875 \\
CMIN/DF & 1.129 & 2.533 \\
p-value & .172 & 0.000 \\
GFI & .929 & .624 \\
CFI & .985 & .720 \\
TLI & .989 & .697 \\
NFI & .917 & .613 \\
RMESA & .027 & .095 \\
\hline
\end{tabular}

As shown in Table 5, although chi-square per degree of freedom ratio $\left(x^{2} / \mathrm{df}=1.12\right)$ and root mean square error of approximation (RMSEA=.027) did change for the final model, the incremental fit index $(\mathrm{GFI}=.92)$, Tucker-Lewis index (TLI = 0.98), Goodness-of- Fit Index (GF I $=.85)$, Normed Fit Index (NFI=.91) and comparative fit index $(\mathrm{CFI}=0.98)$ indicated a better fit to the data after deleting the low-factor loading items. 


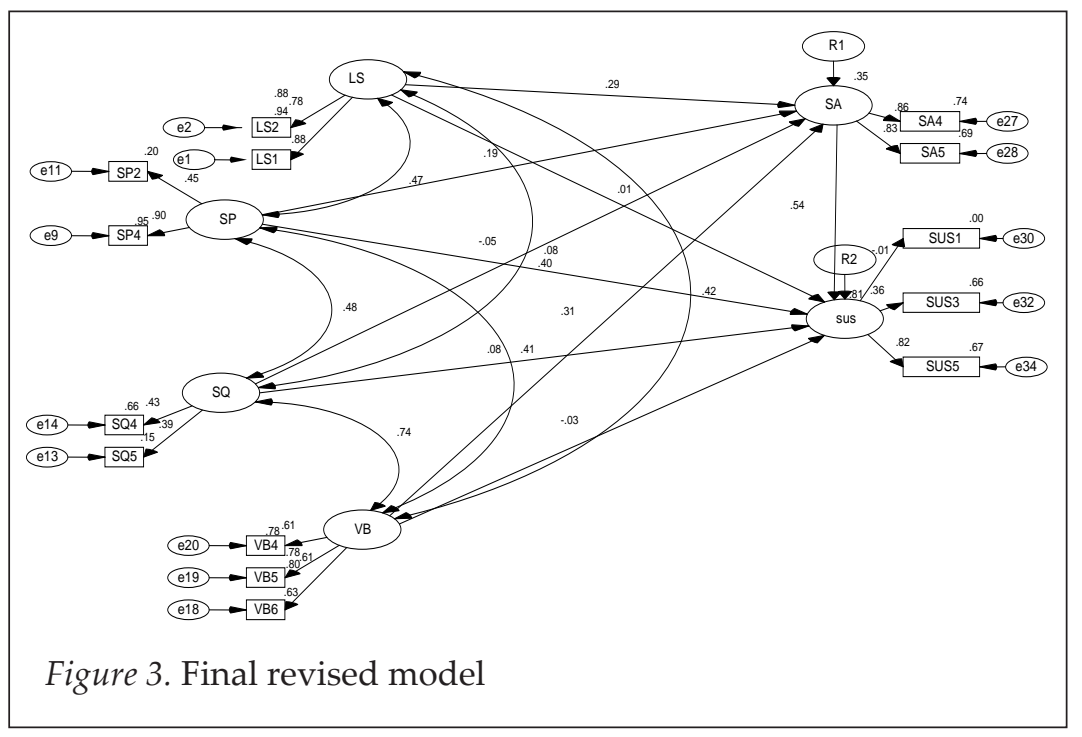

\section{Hypotheses Results}

Since the hypothesised model did not achieve the fit model $(p<.000)$, the explanation of the hypotheses result is based on the Revised Model (RM), which achieved a model fit of $\mathrm{p}$-value $=.172(>0.05)$ (Figure 3$)$. The revised model produces regression standardized estimates direct effect readings (Beta), as shown in Table 6. Some of the hypotheses are supported and some of these hypotheses are not supported.

Table 6

Direct Impact Revised Model (RM): Standardized Regression Weights

\begin{tabular}{cclccccc}
\hline $\mathrm{H}$ & Exog & $\rightarrow$ & Endo & Std.estim & C.R & $\mathrm{P}$ & Evidence \\
\hline $\mathrm{H} 1$ & $\mathrm{LS}$ & $\longrightarrow$ & SA & .114 & 2.312 & .041 & Supported \\
$\mathrm{H} 2$ & $\mathrm{SP}$ & $\rightarrow$ & SA & .011 & .144 & .885 & Not supported \\
$\mathrm{H} 3$ & $\mathrm{SQ}$ & $\rightarrow$ & SA & .100 & 1.420 & .156 & Not supported \\
$\mathrm{H} 4$ & $\mathrm{VB}$ & $\rightarrow$ & SA & .206 & 2.705 & .007 & Supported \\
$\mathrm{H} 5$ & $\mathrm{LS}$ & $\rightarrow$ & SUS & .175 & 3.042 & .002 & Supported \\
$\mathrm{H} 6$ & $\mathrm{SP}$ & $\rightarrow$ & SUS & .068 & 1.004 & .315 & Not supported \\
$\mathrm{H} 7$ & $\mathrm{SQ}$ & $\longrightarrow$ & SUS & .005 & .080 & .936 & Not supported \\
$\mathrm{H} 8$ & $\mathrm{VB}$ & $\rightarrow$ & SUS & .056 & .828 & .408 & Not supported \\
$\mathrm{H} 9$ & $\mathrm{SA}$ & $\rightarrow$ & SUS & .316 & 4.779 & $* * *$ & Supported \\
\hline
\end{tabular}

166 IJMS 18 (1), 155-172 (2011) 


\section{Mediating Effect Analysis of Revised Model}

A mediating effect is created when a third variable/construct intervenes between two other related constructs. Regarding the Revised Model there is one mediating effect of strategic alignment. According to Hair et al., (2006) if the total direct effect is more than the total indirect effect, there is no mediating effect; if the total direct effect is less than the total indirect effect, there is a full mediating effect; and if the total direct effect is equal to the total indirect effect. Then for the partial mediating effect as shown in Table 8, we tested the mediating effects of strategic alignment in the relationship between leadership, structure and process, service quality, values and beliefs and sustainable competitive advantage.

Table 7

Mediating Effect of Strategic Alignment

\begin{tabular}{ccccccc}
\hline Hypothesis & From & Mediation & To & $\begin{array}{c}\text { Total direct } \\
\text { effect }\end{array}$ & $\begin{array}{c}\text { Total indirect } \\
\text { effect }\end{array}$ & Mediating \\
\hline H10 & LS & SA & SUS & .175 & .036 & Not mediating \\
H11 & SP & SA & SUS & .068 & .003 & Not mediating \\
H12 & SQ & SA & SUS & .005 & .03 & Full mediating \\
H13 & VB & SA & SUS & .056 & .065 & Full mediating \\
\hline
\end{tabular}

Furthermore, Table 8 below indicates that the four exogenous variables (leadership, structure and process, service quality, values and beliefs) jointly explained 35 percent variance in SA, and the same four exogenous variables (leadership, structure and process, service quality, values and beliefs) jointly explained 36 percent variance in SUS.

Table 8

Squared Multiple Correlation Results

\begin{tabular}{lc}
\hline Endogenous Variables & Squared Multiple Correlation $(\mathrm{SMC})=\mathrm{R}^{2}$ \\
\hline SA & $35 \%$ \\
SUS & $36 \%$ \\
\hline
\end{tabular}

\section{Discussion}

This study is concerned with an empirical investigation of the success factors that could affect strategic alignment and consequently

IJMS 18 (1), 155-172 (2011) 167 
achieve sustainable competitive advantage. The Revised Model indicates that it has accomplished model fit and while supporting seven hypotheses, it does not support six further hypotheses. As hypothesised (H1), leadership was found to have a significant positive effect on strategic alignment $(\beta=.114 ; \mathrm{CR}=2.312 ; \mathrm{p}=.041)$. This result means that higher levels of communication through faceto-face, electronic mail and memos or through regular meetings lead to better strategic alignment in Jordanian public shareholding firms. Therefore, $\mathrm{H} 1$ is supported. The positive relationship between business-IT interaction and strategic alignment is consistent with the findings of Lind and Zmud (1991), Earl and Feeny (1994), Reich and Benbasat (2000), and Johnson and Lederer (2005), that the interaction between IT and business managers was highly correlated with the degree of convergence between the two parties concerning the strategic role of IT in the firm. Structure and process $(\beta=.011 ; C R=.144 ; p=.885)$ was found to have an insignificant effect on strategic alignment. This finding implies that Jordanian firms need to make sure of the association between the IT plan and the business plan. Most of the literature in previous studies indicated that it is necessary to involve IT strategy with business strategy (Ward \& Peppared, 1999); therefore, H2 is not supported. The third hypothesis suggests a positive relationship between service quality and strategic alignment $(\beta=.100 ; C R=1.420 ; p=.156)$. The finding shows that service quality has an insignificant effect on strategic alignment. This could mean that there is disagreement on the servicelevel agreement between IT strategy and business strategy causing an insignificant effect on the alignment between them. Therefore, H3 is not supported. This result is consistent with the finding of Pitt et al., (1995). In addition, this study found that (values and beliefs) have a positive effect on strategic alignment $(\beta=.206$; $\mathrm{CR}=$ 2.705; $p=.007$ ). This finding suggests that a positive and successful strategic alignment can be formed if there is acceptance of the new technology from the employees. This requires the need of rapid technology from IT managers to update themselves to redesign work which make association between the objectives for IT strategy and business strategy. This result is consistent with $\mathrm{Al}$ Admour and Shunak (2009). Therefore,H4 is supported. Strategic alignment was found to have a significant positive effect on sustainable competitive advantage $\left(\beta=.316 ; C R=4779 ; \mathrm{p}={ }^{* * *}\right)$. This finding shows that the alignment in Jordanian firms has an effect on the firms' sustainable competitive advantage. Therefore, H9 is supported, This is to say the firms that pursue strategic alignment have greater ability to enhance their sustainable competitive advantage. Furthermore, the result of this study shows a direct positive effect of leadership on sustainable 
competitive advantage. However, (values and beliefs), structure and process, and service quality do not have any direct effect on sustainable competitive advantage. Therefore, H5 is supported but H6, H7, H8 are not supported as Table 6 above shows. Finally, the results show that strategic alignment mediates the relationship between service quality and values and beliefs. Therefore, H12, H13 are supported but there is no mediating effect on the relationship between leadership, (structure and process) and strategic alignment on sustainable competitive advantage. Therefore, H10, H11 are not supported.

\section{Conclusion}

In the business world, where flexibility and adaptability are critical, failure to leverage IT may seriously hamper the firm's sustainable competitive advantage, especially in today's global, informationintensive world. Therefore, the need to obtain strategic alignment between business and IT strategies is paramount. The motivation for this study was to propose a theoretical model that determines the impact of several contextual variables (leadership, structure and processe service quality, and values and beliefs) on IT-business strategic alignment, and how such alignment impacts a firm's sustainable competitive advantage. The results of some hypotheses indicated an effect on strategic alignment while others had an insignificant effect on strategic alignment. In addition, strategic alignment has a mediating effect on the relationship between service quality, values and beliefs and sustainable competitive advantage. Therefore, firms in Jordan should have concern for strategic alignment to enhance their competitive position and sustain this advantage. This study will be useful for both academicians and practitioners. From the academic perspective, this study aspires to fill the gap of the incomplete causal chains between IT investments and sustainable competitive advantage. In addition, this study utilizes Chan et al.,'s (2006), and Chan and Reich's (2007) recommendations, by further developing and validating a comprehensive model to assess strategic alignment mechanisms within an organization.

\section{Acknowledgements}

I would like to express my sincere gratitude to my supervisor Prof. Dr. Zulkhairi Md. Dahalin for his guidance throughout this work.

IJMS 18 (1), 155-172 (2011) 169 


\section{References}

Aldhmour, F. (2009). Towards understanding the relationship between information and communication technology and competitive advantage in a developing economy. International Review of Business Research Papers, 5(1), 307-320.

Amman Stock Exchange. (n.d.). Retrieved from http://www.ase.com. jo

Bagozzi, R., \& Yi, Y. (1988). On the evaluation of structural equation models. Journal of the Academy of Marketing Science, 16(1), 74-94.

Coakes, S. J., \& Steed, L. G. (2003). SPSS analysis without anguish. Sydney, Australia: John Wiley \& Sons.

Chan, Y., \& Reich, B. (2007). IT alignment: What have we learned? Journal of Information Technology, 22(4), 297-315.

Croteau, A., \& Bergeron, F. (2001). An information technology trilogy: Business strategy, technological deployment and organizational performance. The Journal of Strategic Information Systems, 10(2), 77-99.

Chan, Y., Sabherwal, R., \& Thatcher, J. (2006). Antecedents and outcomes of strategic IS alignment: An empirical investigation. IEEE Transactions on Engineering Management, 53(1), 27-47.

De Villiers, R. (2006). Sources of sustainable competitive advantage for business operating in global market place. (Unpublished doctoral dissertation). University of Pretoria: The USA.

Dong, X., Liu, Q., \& Yin, D. (2008). Business performance, business strategy, and information system strategic alignment: An empirical study on Chinese firms. Tsinghua Science and Technology, 13(3), 348-354.

Day, G. S. (1984). Strategic market planning: The pursuit of competitive advantage. St. Paul, MN: West Publishing.

Fornell, C., \& Larcker, D. (1981). Evaluating structural equation models with unobservable variables and measurement error. Journal of Marketing Research, 18(1), 39-50.

Grindley, K. (1992). Information systems issues facing senior executives: The culture gap. The Journal of Strategic Information Systems, 1(2), 57-62.

Galliers, R., Meriali, Y., \& Spearing, L., (1994). Coping with information technology? How British executives perceive the key information systems management issues in the mid-1990s. Journal of Information Technology, 9, 233-238.

Henderson, J., \& Venkatraman, N. (1993). Strategic alignment: Leveraging information technology for transforming organizations. IBM systems Journal, 32(1), 4-16. 
Hair, J., Black, W., Babin, B., Anderson, R., \& Tatham, R. (1998). Multivariate data analysis. Upper Saddle River, NJ: Prentice Hall.

Hair, J., Black, W., Babin, B., Anderson, R., \& Tatham, R. (2006). Multivariate data analysis. Upper Saddle River, NJ: Prentice Hall.

Johnson, A., \& Lederer, A. (2010). CEO/CIO mutual understanding, strategic alignment, and the contribution of IS to the organization. Information \& Management, 47(3), 138-149.

Kearns, G. S., \& Lederer, A. L. (2001). Strategic IT-alignment: A model for competitive advantage. Proceedings of the 22nd ICIS, 1-12, Barcelona.

Luftman, J. (2003). Measure your business-IT alignment. Optimize: Business Execution for CIOs Magazine, 26.

Luftman, J., Kempaiah, R., \& Nash, E. (2006). Key issues for IT executives 2005. MIS Quarterly Executive, 5(2), 81-101.

Luftman, J., \& Brier, T. (1999). Achieving and sustaining business-IT alignment. California Management Review, 42(1), 109-122.

Masa'deh, R., \& Kuk, G. (2009, August 7-11). Antecedents and intermediaries between strategic alignment and firm performance. Proceedings of the 2009 Conference of the Academy of Management Annual Meeting(AOM), Illinois, Chicago, U.S.A.

Nunnally, J. (1970). Psychometric methods. NY: McGraw-Hill.

Oana, V. (2010).Strategic alignment of ERP implementation stages: An empirical investigation. Information $\mathcal{E}$ Management, 47(3), 158-166.

Pierce, A. C. (2002). The effect of business and information technology strategic alignment on information technology investment returns and corporate performance (Unpublished doctoral dissertation). Nova Southeastern University.

Porter, M. E. (1985). Competitive advantage: Creating and sustaining superior performance. New York: The Free Press.

Pallant. (2007). SPSS survival manual (3rd ed.). Sydney: McGraw Hill.

Pitt, L., Watson, R., \& Kavan, C. (1995). Service quality: A measure of information systems effectiveness. MIS Quarterly, 19(2), 173187.

Reich, B., \& Benbasat, I. (1996). Measuring the linkage between business and information technology objectives. MIS Quarterly, 20(1), 55-81.

Reich, B., \& Benbasat, I. (2000). Factors that influence the social dimensions of alignment between business and information technology objectives. MIS Quarterly, 24(1), 81-113.

Sabherwal, R., \& Chan, Y. (2001). Alignment between business and IS strategies: A study of prospectors, analyzers, and defenders. Information Systems Research, 12(1), 11-33.

IJMS 18 (1), 155-172 (2011) 171 
Sage, A. P. (2002). Information technology. Retrieved from http://www. accessscience.com, DOI 10.1036/1097-8542.757582

Ward, J., \& Griffiths, P. (1999). Strategic planning for information systems. New York: John Wiley \& Sons.

Ward, J., \& Peppard, J. (1999). 'Mind the gap': Diagnosing the relationship between the IT organization and the rest of the business. Journal of Strategic Information Systems, 8(1), 29-60.

Ward, J., \& Peppard, J. (2002). Strategic planning for information systems (3rd ed.). New York: John Wiley \& Sons. 